Article

\title{
A Comparative Study of Bulk Parameterization Schemes for Estimating Cloudy-Sky Surface Downward Longwave Radiation
}

\author{
Jie Cheng ${ }^{1,2, * \mathbb{C}}$, Feng Yang ${ }^{1}$ and Yamin Guo ${ }^{1} \mathbb{C}$ \\ 1 State Key Laboratory of Remote Sensing Science, Faculty of Geographical Science, Beijing Normal \\ University; Beijing 100875, China; yftaurus@mail.bnu.edu.cn (F.Y.); guoym_gis@163.com (Y.G.) \\ 2 Institute of Remote Sensing Science and Engineering, Faculty of Geographical Science, \\ Beijing Normal University, Beijing 100875, China \\ * Correspondence: Jie_Cheng@bnu.edu.cn
}

Received: 9 January 2019; Accepted: 26 February 2019; Published: 5 March 2019

\begin{abstract}
Parameterization schemes (bulk formulae) are widely used to estimate all-sky surface downward longwave radiation (SDLR) due to the simple, readily available inputs and acceptable accuracy from local to regional scales. Seven widely used bulk formulae are evaluated using the ground measurements collected from 44 globally distributed flux measurement sites of five networks. The Bayesian model averaging (BMA) method is introduced to integrate multiple bulk formulae to obtain an estimate of cloudy-sky SDLR for the first time. The second multiple linear regression model of Carmona et al. (2014) performs the best, with BIAS, RMSE, and $\mathrm{R}^{2}$ of zero, $20.13 \mathrm{~W} \cdot \mathrm{m}^{-2}$ and 0.87 , respectively. The BMA method can achieve balanced results that are close to the accuracy of the second multiple linear regression model of Carmona et al. (2014) and better than the average accuracy of seven bulk formulae, with BIAS, RMSE, and $\mathrm{R}^{2}$ of $-1.08 \mathrm{~W} \cdot \mathrm{m}^{-2}, 21.99 \mathrm{~W} \cdot \mathrm{m}^{-2}$ and 0.87, respectively. In addition, the bulk formula of Crawford and Duchon (1999) is preferred if there is insufficient data to calibrate the bulk formulae because it does not need local calibration and has an acceptable accuracy, with BIAS, RMSE, and $\mathrm{R}^{2}$ of $0.96 \mathrm{~W} \cdot \mathrm{m}^{-2}, 26.58 \mathrm{~W} \cdot \mathrm{m}^{-2}$ and 0.82 , respectively. The effects of climate type, land cover type, and surface elevation are also investigated to fully assess the applicability of each bulk formula and BMA. In general, there is no cloudy-sky bulk parametrization scheme that can be successfully applied everywhere.
\end{abstract}

Keywords: SDLR; all-sky; BMA; surface radiation budget; remote sensing

\section{Introduction}

The radiation budget at the Earth's surface is an important factor that determines land surface processes such as evapotranspiration, oceanic and atmospheric circulations [1,2]. Surface downward longwave radiation (SDLR, 4-100 $\mu \mathrm{m}$ ) is one of four components required to calculate the Earth's surface radiation budget [3-5]. Usually, a considerable part of the earth's surface is covered by clouds [6]. In cloudy sky, SDLR is emitted from clouds (aerosol, water droplets, and ice crystals) and atmosphere columns $\left(\mathrm{H}_{2} \mathrm{O}, \mathrm{CO}_{2}\right.$, and $\mathrm{O}_{3}$ molecules) between the cloud base and the surface. Numerous studies demonstrated that clouds have a nonneglectable contribution to SDLR, especially in the thermal infrared atmosphere window [7-9], because clouds can simultaneously absorb solar radiation and re-emit outgoing longwave radiation (OLR) to space and SDLR to the surface.

SDLR can be accurately measured using ground-based instruments (e.g., pyrgeometer). However, this method is relatively expensive and sensitive and has spatially sparse coverage at the global scale [10]. Therefore, many researchers have used remote sensing and meteorological data to estimate 
high spatial-temporal SDLR [11-14], and many SDLR retrieval algorithms have been proposed. These algorithms can be classified into three categories: physical, parameterized, and statistical methods $[15,16]$. Relatively simple parameterization schemes are highly praised in that they only require a limited input set of atmospheric variables and have acceptable accuracy [17-19]. For example, Wang and Liang [20] applied the bulk formulae of Brunt [21] and Brutsaert [22] to estimate all-sky SDLR from global available meteorological observations to calculate the decadal variation in SDLR. The general form of the parameterization scheme (also called the bulk formula) is expressed as

$$
S D L R=\sigma \varepsilon_{e f f} T_{e f f}^{4}
$$

where $\varepsilon_{e f f}$ is the effective emissivity of the atmosphere under all-sky conditions, $T_{e}$ is atmospheric effective temperature, and $\sigma$ is the Stefan-Boltzmann constant. Most of the bulk formulae are applicable to clear-sky cases [12,21-24], and few derive all-sky SDLR [17,25-30]. Under cloudy-sky conditions, the liquid water and ice absorb and emit longwave radiation more effectively than water in the vapor phase. Thus, clouds increase SDLR significantly, and cloud cover is usually introduced to calculate atmospheric effective emissivity $[7,15,25]$.

Numerous studies have been conducted to analyze the advantages, shortcomings and applicability of these bulk formulae. For example, Kjaersgaard et al. [31] evaluated the performance of 20 clear-sky bulk formulae using long-term ground measurements at two sites in Demark. Their results suggested that four bulk formulae, proposed by Swinbank [32], Brutsaert [22], and Prata [23] and the Food and Agricultural Organization (1990) parameterization of the Brunt [21] model, have smaller discrepancies than the other bulk formulae. Kjaersgaard et al. [31] combined the above four models with the cloudy-sky bulk formulae of Korsgaard [33] and Crawford and Duchon [26] to evaluate the accuracy of SDLR estimates. The mean bias errors of the two combinations ranged from -8 to $8 \mathrm{~W} \cdot \mathrm{m}^{-2}$, and the root mean square errors (RMSEs) ranged from 23 to $30 \mathrm{~W} \cdot \mathrm{m}^{-2}$. Flerchinger et al. [34] investigated the accuracy of 13 clear-sky SDLR bulk schemes at 21 sites across North America and China. Their study indicated that the bulk schemes developed by Dilley et al. [35], Prata [23], and Angstrom [36] are good at predicting surface SDLR. Flerchinger et al. [34] combined the cloud-correction methods of Kimball and Idso [9], Unsworth and Monteith [37], and Crawford and Duchon [26] with the clear-sky formulation of Dilley and O'Brien [35] to obtain estimates of the all-sky SDLR. The results showed that the average root mean square deviation across all sites for three cloud corrections was approximately 24 to $25 \mathrm{~W} \cdot \mathrm{m}^{-2}$ for 30-minute or hourly estimates. Zhu et al. [19] comprehensively assessed all-sky atmospheric emissivity using 13 clear-sky bulk schemes combined with 10 cloud corrections at five sites in high mountain regions of the Tibetan Plateau. The results showed that the best all-sky parameterization scheme for the five sites was Dilley and O'Brien's A model [35] for clear-sky conditions combined with Sicart et al.'s A cloud correction [38], with a mean RMSE of $26.3 \mathrm{~W} \cdot \mathrm{m}^{-2}$ and a mean MBE of zero. These clear-sky or all-sky bulk formulae have different accuracies at local scales. If they were applied directly to different areas, the inversion accuracy would be reduced and their applicability would be suppressed. Which bulk formula is best adapted to SDLR estimate under a specific circumstance remains unclear. In addition, selection of a suitable bulk formula lacks guidance.

A few studies explored new ways to estimate all-sky SDLR by taking advantage of existing bulk formulae with good performance. They found that the Bayesian model averaging (BMA) method is effective to estimate clear-sky SDLR $[39,40]$. The estimation potential of BMA for all-sky SDLR and its accuracy and applicability have not been determined. Thus, the purpose of this study is to investigate the accuracy and applicability of widely used cloudy-sky bulk formulae and the utility of BMA in estimating cloudy-sky SDLR. First, bulk formulae for cloudy-sky SDLR estimate are calibrated and integrated using BMA. Then, the bulk formulae and BMA are validated using ground measurements. Finally, the performance of the bulk formulae and BMA are assessed under the circumstances of different climate types, land covers and surface elevations. 


\section{Materials and Methods}

\subsection{Ground Measurements}

The surface radiation network can provide long-term, accurate records of components of the surface radiation budget and meteorological observations, which can be used to detect important changes in the Earth's radiation field at the Earth's surface and support the validation and confirmation of satellite and computer model estimates [20]. After filtering the poor-quality data using the built-in quality control (QC) information, high quality ground-measured SDLR, surface downward shortwave radiation and meteorological variables (air temperature and relative humidity) collected at 44 globally distributed sites from 5 independent surface radiation networks, including 14 sites from the Baseline Surface Radiation Network (BSRN) [41], 12 sites from AmeriFlux [42], 8 sites from AsiaFlux [42], 6 sites from SURFRAD [43], and 4 sites from the Coordinated Energy and Water Cycle Observations Project (CEOP) [44] (Figure 1), are used in this study. These sites have a latitude span of $78^{\circ} \mathrm{W}$ to $70^{\circ} \mathrm{E}$, with elevations ranging from $4 \mathrm{~m}$ to $5038 \mathrm{~m}$, and they cover a variety of land types, including bare land, desert, cropland, grassland, and forest. The 44 sites represent different climate and ecosystem conditions. Table 1 gives detailed descriptions of these sites.

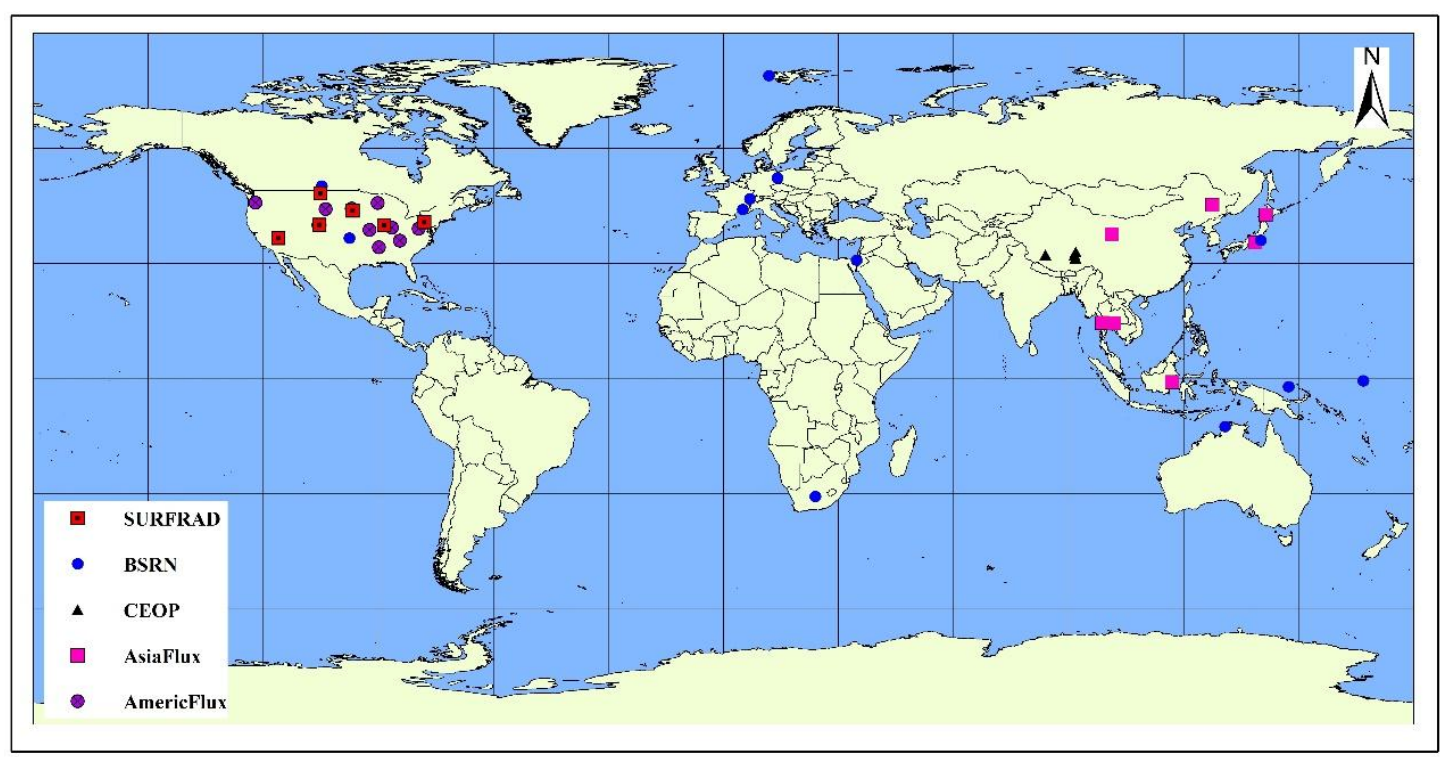

Figure 1. Spatial distribution of the selected 44 sites from 5 independent surface radiation networks. 
Table 1. Selected sites in the surface radiation networks.

\begin{tabular}{|c|c|c|c|c|c|c|c|c|c|}
\hline NO. & Short Name & Full Name & Latitude & Longitude & Elevation (m) & Land Cover & $\begin{array}{c}\text { Climate } \\
\text { Type }\end{array}$ & $\begin{array}{c}\text { Temporal } \\
\text { Resolution }\end{array}$ & Time Period \\
\hline 1 & Bondville $^{1}$ & Bondville, Illinois & 40.05 & -88.37 & 213 & Cropland & Dfa & $3 \mathrm{~min}$ & 2003-2005 \\
\hline 2 & Boulder $^{1}$ & Boulder, Colorado & 40.13 & -105.24 & 1689 & Grassland & BSk & $3 \mathrm{~min}$ & 2003-2005 \\
\hline 3 & Fort Peck ${ }^{1}$ & Fort Peck, Montana & 48.31 & -105.10 & 634 & Grassland & BSk & $3 \mathrm{~min}$ & 2003-2005 \\
\hline 4 & Desert Rock ${ }^{1}$ & Desert Rock, Nevada & 36.63 & -116.02 & 1007 & Desert & BWh & $3 \mathrm{~min}$ & 2003-2005 \\
\hline 5 & Penn State ${ }^{1}$ & PennState, Pennsylvania & 40.72 & -77.93 & 376 & Cropland & $\mathrm{Dfb}$ & $3 \mathrm{~min}$ & 2003-2005 \\
\hline 6 & Sioux Falls ${ }^{1}$ & Sioux Falls, South Dakota & 43.73 & -96.62 & 473 & Cropland & Dfa & $3 \mathrm{~min}$ & 2003-2005 \\
\hline 7 & US-Blk ${ }^{2}$ & Black Hills & 44.16 & -103.65 & 1718 & Evergreen needle leaf forest & $\mathrm{Dfb}$ & $30 \mathrm{~min}$ & 2004-2006 \\
\hline 8 & US-Bo $2^{2}$ & Bondville (companion site) & 40.01 & -88.29 & 219.3 & Cropland & Dfa & $30 \mathrm{~min}$ & 2004-2006 \\
\hline 9 & US-Bkg ${ }^{2}$ & Brookings & 44.35 & -96.84 & 510 & Grasslands & Dfa & $30 \mathrm{~min}$ & $2004-2006$ \\
\hline 10 & US-CaV ${ }^{2}$ & Canaan Valley & 39.06 & -79.42 & 994 & Grasslands & $\mathrm{Cfb}$ & $30 \mathrm{~min}$ & 2004-2006 \\
\hline 11 & US-NR1 ${ }^{2}$ & Niwot Ridge Forest & 40.03 & -105.55 & 3050 & Evergreen needle leaf forest & Dfc & $30 \mathrm{~min}$ & $2001-2003$ \\
\hline 12 & US-FPe ${ }^{2}$ & Fort Peck & 48.31 & -105.1 & 634 & Grassland & BSk & $30 \mathrm{~min}$ & 2003-2005 \\
\hline 13 & US-Goo ${ }^{2}$ & Goodwin Creek & 34.25 & -89.87 & 87 & Grasslands & Cfa & $30 \mathrm{~min}$ & 2003-2005 \\
\hline 14 & US-MMS $^{2}$ & Morgan Monroe State Forest & 39.32 & -86.41 & 275 & Deciduous broadleaf forest & Cfa & $30 \mathrm{~min}$ & $2001-2003$ \\
\hline 15 & US-WBW $^{2}$ & Walker Branch Watershed & 35.96 & -84.29 & 283 & Deciduous broadleaf forest & Cfa & $30 \mathrm{~min}$ & 2003-2005 \\
\hline 16 & US-Wrc ${ }^{2}$ & Wind River Crane Site & 45.82 & -121.95 & 371 & Evergreen needleleaf forest & $\mathrm{Csb}$ & $30 \mathrm{~min}$ & 2003-2005 \\
\hline 17 & US-WCr ${ }^{2}$ & Willow Creek & 45.81 & -90.08 & 520 & Deciduous broadleaf forest & $\mathrm{Dfb}$ & $30 \mathrm{~min}$ & 2003-2005 \\
\hline 18 & US-MOz ${ }^{2}$ & Missouri Ozark Site & 38.74 & -92.20 & 220 & Deciduous broadleaf forest & $\mathrm{Cfa}$ & $30 \mathrm{~min}$ & 2003-2005 \\
\hline 19 & $\mathrm{QHB}^{3}$ & Qinghai Flux Research Site & 37.61 & 101.33 & 3250 & Grasslands & BSk & $15 \mathrm{~min}$ & 2003-2004 \\
\hline 20 & $\mathrm{MKL}^{3}$ & Mae Klong & 14.58 & 98.84 & 231 & Mix forest & Am & $15 \mathrm{~min}$ & 2003-2004 \\
\hline 21 & $\mathrm{TKY}^{3}$ & Takayama & 36.15 & 137.42 & 1420 & Deciduous broadleaf forest & $\mathrm{Dfb}$ & $15 \mathrm{~min}$ & 2003-2005 \\
\hline 22 & $\mathrm{TMK}^{3}$ & Tomakomai Flux & 42.74 & 141.52 & 140 & Deciduous needle leaf forest & $\mathrm{Dfb}$ & $15 \mathrm{~min}$ & $2001-2003$ \\
\hline 23 & $\mathrm{BKS}^{3}$ & Bukit Soeharto & -0.86 & 117.04 & 20 & Evergreen broadleaf forest & Af & $15 \mathrm{~min}$ & $2001-2002$ \\
\hline 24 & FJY3 & Fujiyoshida & 35.45 & 138.76 & 1030 & Deciduous needleleaf forest & $\mathrm{Cfa}$ & $15 \mathrm{~min}$ & 2000 \\
\hline 25 & $\mathrm{LSH}^{3}$ & Laoshan & 45.28 & 127.58 & 340 & Deciduous needleleaf forest & $\mathrm{Cfc}_{\mathrm{C}}$ & $15 \mathrm{~min}$ & 2002 \\
\hline 26 & $\mathrm{SKR}^{3}$ & Sakaerat & 14.49 & 101.92 & 543 & Evergreen broadleaf forest & Aw & $15 \mathrm{~min}$ & $2001-2003$ \\
\hline 27 & $\mathrm{Amdo}^{4}$ & AmdoTower & 32.24 & 91.62 & 4695 & Bare land & $\mathrm{ET}$ & $60 \mathrm{~min}$ & $2002-2004$ \\
\hline 28 & $\mathrm{BJ}^{4}$ & BJTower & 31.37 & 91.90 & 4509 & Bare land & ET & $60 \mathrm{~min}$ & $2002-2004$ \\
\hline 29 & $\mathrm{D} 105^{4}$ & D105AWS & 33.06 & 91.94 & 5038 & Bare land & ET & $60 \mathrm{~min}$ & $2002-2004$ \\
\hline 30 & Gaize $^{4}$ & Gaize & 32.30 & 84.05 & 4416 & Bare land & Dwb & $60 \mathrm{~min}$ & 2002-2004 \\
\hline 31 & $\mathrm{BOU}^{5}$ & Boulder & 40.05 & -105.01 & 1577 & Grasslands & BSk & $1 \mathrm{~min}$ & $2003-2005$ \\
\hline 32 & $\mathrm{CAR}^{5}$ & Carpentras & 44.08 & 5.06 & 100 & Cultivated & Csb & $1 \mathrm{~min}$ & $2003-2005$ \\
\hline 33 & $\mathrm{DAR}^{5}$ & Darwin & -12.43 & 130.89 & 30 & Grasslands & Aw & $1 \mathrm{~min}$ & $2003-2005$ \\
\hline 34 & LIN $^{5}$ & Lindenberg & 52.21 & 14.12 & 125 & Cultivated & $\mathrm{Dfb}$ & $1 \mathrm{~min}$ & $2003-2005$ \\
\hline 35 & MAN $^{5}$ & Momote & -2.06 & 147.43 & 6 & Grasslands & Af & $1 \mathrm{~min}$ & 2003-2005 \\
\hline
\end{tabular}


Table 1. Cont

\begin{tabular}{|c|c|c|c|c|c|c|c|c|c|}
\hline NO. & Short Name & Full Name & Latitude & Longitude & Elevation (m) & Land Cover & $\begin{array}{c}\text { Climate } \\
\text { Type }\end{array}$ & $\begin{array}{c}\text { Temporal } \\
\text { Resolution }\end{array}$ & Time Period \\
\hline 36 & $\mathrm{NAU}^{5}$ & Nauru Island & -0.52 & 166.92 & 7 & Rock & Af & $1 \mathrm{~min}$ & 2003-2005 \\
\hline 37 & NYA $^{5}$ & Ny-Ålesund & 78.93 & 11.93 & 141 & Tundra & ET & $1 \mathrm{~min}$ & 2003-2005 \\
\hline 38 & $\mathrm{PAY}^{5}$ & Payerne & 46.82 & 6.94 & 491 & Cultivated & Dfb & $1 \mathrm{~min}$ & 2003-2005 \\
\hline 39 & $\mathrm{REG}^{5}$ & Regina & 50.21 & -104.71 & 578 & Cultivated & $\mathrm{Dfb}$ & $1 \mathrm{~min}$ & $2003-2005$ \\
\hline 40 & $\mathrm{E} 13^{5}$ & Southern Great Plains & 36.61 & -97.49 & 318 & Grasslands & $\mathrm{Cfa}$ & $5 \mathrm{~min}$ & $2003-2005$ \\
\hline 41 & $\mathrm{TAT}^{5}$ & Tateno & 36.05 & 140.13 & 25 & Grasslands & $\mathrm{Cfa}$ & $1 \mathrm{~min}$ & $2003-2005$ \\
\hline 42 & $\mathrm{DAA}^{5}$ & De Aar & -30.7 & 23.99 & 1287 & Desert & BWk & $5 \mathrm{~min}$ & $2002-2004$ \\
\hline 43 & $\mathrm{GVN}^{5}$ & Georg von Neumayer & -70.65 & -8.25 & 42 & Ice & $\mathrm{EF}$ & $1 \mathrm{~min}$ & 2003-2005 \\
\hline 44 & $\mathrm{SBO}^{5}$ & Sede Boqer & 30.86 & 34.78 & 500 & Desert & BWk & $1 \mathrm{~min}$ & 2003-2005 \\
\hline
\end{tabular}

Note: 1, 2, 3, 4, and 5 represent SURFRAD sites, AmeriFlux sites, AsiaFlux sites, CEOP sites, and BSRN sites, respectively. 


\subsection{Methods}

\subsubsection{Cloudy-Sky Bulk Formulae}

Cloudy sky is identified using the cloud fraction function c [26], which is defined as

$$
\mathrm{c}=1-\frac{S w \downarrow}{S w \downarrow 0}
$$

where $S w \downarrow$ is the observed downward shortwave radiation, $S w \downarrow 0$ is the theoretical value of downward shortwave radiation; when $c>0.05$, we define the situation as cloudy sky.

The equation of the selected cloudy-sky bulk formulae are shown in Table 2. Herein, we briefly described these bulk formulae. More details please refer to their respective papers. The bulk formula of Jacobs [29] is similar to that of Lhomme et al. [27], who proposed a cloudy-sky bulk formula by combining the bulk formula of Brutsaert [22] and a correction for cloudiness using the measurements obtained from two different sites on the Andean Altiplano, which is a vast plateau lying at an average altitude of $4000 \mathrm{~m}$. The bulk formula of Maykut and Church [45] was developed using the five-year observations of the radiation climate near Point Barrow, Alaska. Konzelmann et al. [28] developed the bulk formula to estimate cloudy-sky SDLR using the meteorological measurements from various projects on West Greenland. Crawford and Duchon [26] developed an improved parameterization scheme for estimating effective atmospheric emissivity by explicitly incorporating the fractional cloudiness using the data from the Atmospheric Radiation Measurement (ARM) program. Carmona et al. [25] proposed two multiple linear regression models to estimate SDLR for all sky conditions over a sub-humid region in Argentina. Clearly, these bulk formulae are likely to be specific to the atmospheric circumstances under which they were developed, and should be handled with care when applying to other conditions.

According to the study of Guo et al. [40], the clear-sky bulk formula of Carmona et al. [25] has good performance at global scale. Thus, we selected their bulk formula to calculate the clear-sky SDLR in the cloudy-sky bulk formulae shown in Table 2. The clear sky bulk formula of Carmona et al. [25] is expressed as

$$
S D L R_{c l r}=\left(\alpha+\beta T_{a}+\gamma R H\right) \times \sigma T_{a}^{4}
$$

where $\alpha, \beta$, and $\gamma$ are coefficients, and $T_{a}$ and $R H$ are the air temperature and relative humidity at screen level, respectively.

Table 2. Seven cloudy-sky bulk formulae for surface downward longwave radiation (SDLR) estimation.

\begin{tabular}{ccc}
\hline Model & Bulk Formulae & Equation \\
\hline 1 & Jacobs [29] & SDLR $=S D L R_{c l r}\left(1+a_{1} c\right)$ \\
2 & Lhomme et al. [27] & SDLR $=S D L R_{c l r}\left(a_{2}+b_{2} c\right)$ \\
3 & Maykut and Church [45] & SDLR $=S D L R_{c l r}\left(1+a_{3} c^{b_{3}}\right)$ \\
4 & Konzelmann et al. [28] & SDLR $=S D L R_{c l r}\left(1-a_{4} c^{b_{4}}\right)+d_{4} c^{e_{4}} \sigma T^{4}$ \\
5 & Crawford and Duchon [26] & SDLR $=S D L R_{c l r}(1-c)+c \sigma T^{4}$ \\
6 & Carmona1 [25] & SDLR $=\left[\left(a_{6}+b_{6} T+d_{6} R H\right)(1-c)+c\right] \sigma T^{4}$ \\
7 & Carmona2 [25] & SDLR $=\left(a_{7}+b_{7} T+d_{7} R H+e_{7} c\right) \sigma T^{4}$ \\
\hline
\end{tabular}

Note: Carmona1 and Carmona2 denote the first and second multiple linear regression models of Carmona et al. (2014), respectively. The selected seven bulk formulae are abbreviated as Jacobs, Lhomme, MC, Konzelmann, Crawford, Carmona1 and Carmona2, respectively. $a, b, d$, and $e$ are the coefficients, SDLR $R_{c l r}$ is the clear-sky SDLR, $T$ is the screen-level temperature (unit: $\mathrm{K}), \sigma$ is the Stephen-Boltzmann constant $\left(5.67 \cdot 10^{-8} \mathrm{~W} \cdot \mathrm{m}^{-2} \cdot \mathrm{K}^{-4}\right), R H$ is the relative humidity (\%), and $c$ is the cloud fraction.

\subsubsection{Bayesian Model Averaging}

In this study, the Bayesian Model Averaging (BMA) method is introduced to integrate selected bulk formulae for predicting SDLR under all-sky condition for the first time. The BMA method uses the posterior probability as the weight to conduct a weighted average of the possible individual 
models $[46,47]$. The posterior probability reflects the models' predictive performance and can be derived in the training period [46].

We employ $S D L R_{p}$ and $S D L R_{o}$ to denote the predicted and observed SDLRs at a given time, respectively $f_{1}, f_{1}, \cdots f_{n}$ is an ensemble of $\mathrm{n}$ bulk formulae (Table 2 ) used to predict $S D L R_{p}$. According to the total probability formula, the predictive probability density function (PDF) of $S D L R_{p}$ based on the multi-bulk formulae ensemble can be calculated as

$$
\mathrm{p}\left(S D L R_{p} \mid f_{1}, f_{1}, \cdots f_{n}\right)=\sum_{i=1}^{n} \mathrm{p}\left(S D L R_{p} \mid f_{i}\right) \mathrm{p}\left(f_{i} \mid S D L R_{o}\right)
$$

where $\mathrm{p}\left(f_{i} \mid S D L R_{o}\right)$ is the forecast PDF of bulk formula $f_{i}$ alone, and $\mathrm{p}\left(f_{i} \mid S D L R_{o}\right)$ is the posterior probability of bulk formula $f_{i}$, which can reflect how well the bulk formula $f_{i}$ fits the observations. The PDF of BMA is a weighted average of the conditional PDFs of each individual bulk formula, weighted by their posterior model probabilities. The posterior probabilities of all single bulk formulae add up to one, i.e., $\sum_{i=1}^{n} \mathrm{p}\left(f_{i} \mid S D L R_{o}\right)=1$, and they can be viewed as weights $w_{i}$. Equation (4) can be rearranged as:

$$
\mathrm{p}\left(S D L R_{p} \mid f_{1}, f_{1}, \cdots f_{n}\right)=\sum_{i=1}^{n} w_{i} \mathrm{p}\left(S D L R_{p} \mid f_{i}\right)
$$

Assuming the conditional PDF of $S D L R_{p}$ is normally distributed with mean value of $\mathrm{E}$, and variance $\sigma^{2}$. Denote the $\mathrm{g}(\cdot)$ to represent the associated Gaussian PDF of each bulk formula.

$$
\begin{gathered}
\mathrm{p}\left(S D L R_{p} \mid f_{i}\right)=\mathrm{g}\left(S D L R_{p} \mid\left\{E_{i}, \sigma_{i}^{2}\right\}\right) \\
\mathrm{p}\left(S D L R_{p} \mid f_{1}, f_{1}, \cdots f_{n}\right)=\sum_{i=1}^{n} w_{i} \mathrm{~g}\left(S D L R_{p} \mid\left\{E_{i}, \sigma_{i}^{2}\right\}\right)
\end{gathered}
$$

The optimal estimation of SDLR by the BMA method is to derive the conditional expected value of $S D L R_{p}$, which can be written as follows:

$$
\mathrm{E}\left(S D L R_{p} \mid f_{1}, f_{1}, \cdots f_{n}\right)=\sum_{i=1}^{n} w_{i} E_{i}
$$

As a result, the key problem is obtaining the posterior probabilities $w_{i}$ of each model, which makes the estimated $S D L R_{p}$ closest to the measurement $S D L R_{o}$. The $w_{i}$ can be estimated by maximum likelihood from the training data [48]. The EM algorithm is iterative and alternates between the Expectation (or E) step and the Maximization (or M) step to find the maximum likelihood value [49]. Firstly, we assume that all the bulk formulae have the same weight, then the Expectation step can be written as:

$$
z_{i, t}=\frac{w_{i} \mathrm{~g}\left(S D L R_{o, t} \mid\left\{E_{i, t}, \sigma_{i}^{2}\right\}\right)}{\sum_{i=1}^{n} w_{i} \mathrm{~g}\left(S D L R_{o, t} \mid\left\{E_{i, t}, \sigma_{i}^{2}\right\}\right)}
$$

where the $z_{i, t}$ denotes the probability that the bulk formula $i$ to be the best forecaster at training data $t$. The M step will estimate the $w_{i}$ using the $z_{i, t}$ calculated in E step:

$$
\begin{gathered}
w_{i}=\frac{1}{N} \sum_{t} z_{i, t} \\
\sigma_{i}^{2}=\frac{1}{N} \sum_{t} \sum_{i=1}^{n} z_{i, t}\left(E_{i, t}-S D L R_{o, t}\right)^{2}
\end{gathered}
$$

where $N$ is the number of observations in the training dataset, $n$ is the number of bulk formulae. The $\mathrm{E}$ and $\mathrm{M}$ steps are iterated to convergence, and then the $w_{i}$ for each bulk formula is obtained. 


\section{Results and Discussion}

\subsection{Calibration and Validation}

Three indicators, the mean bias error (BIAS, Equation (12)), root-mean-square error (RMSE, Equation (13)) and determination coefficient $\left(R^{2}\right.$, Equation (14)), are used to evaluate the performance of cloudy-sky bulk formulae.

$$
\begin{gathered}
\mathrm{BIAS}=\frac{1}{n} \sum_{i=1}^{n}\left(S D L R_{e, i}-S D L R_{o, i}\right)^{2} \\
\mathrm{RMSE}=\sqrt{\frac{1}{n-1} \sum_{i=1}^{n}\left(S D L R_{e, i}-S D L R_{o, i}\right)^{2}} \\
\mathrm{R}^{2}=1-\frac{\frac{1}{n} \sum_{i=1}^{n}\left(S D L R_{e, i}-S D L R_{o, i}\right)^{2}}{\sum_{i=1}^{n}\left(S D L R_{o, i}-\overline{S D L R_{o, i}}\right)^{2}}
\end{gathered}
$$

where $S D L R_{e, i}$ is the estimated SDLR, $S D L R_{o, i}$ is the observed SDLR, $\overline{S D L R_{o, i}}$ is the mean $S D L R_{0, i}$, and $n$ is the number of samples.

The collected samples in Section 2.1 were used to calibrate and validate the selected cloudy-sky bulk formulae and validate the results integrated by BMA. We randomly divided the collected samples into two parts: two-thirds of samples were used to calibrate the bulk formulae to remove the potential error caused by the local coefficients; the remaining one-third of samples were used to validate the calibrated bulk formulae. To examine the performance of calibration, the bulk formulae with original coefficients were also validated using the same data.

Table 3 shows the variation of coefficients among six bulk formulae. The bulk formula of Crawford and Duchon [26] is not considered. This is due to fact that Crawford and Duchon [26] is a special case of Konzelmann [4], and the corresponding model coefficients are all one. Table 3 shows that the relative variation of the bulk formula coefficients is greater than $30 \%$ except for that of Lhomme [27], and more than half of the bulk formula coefficients are greater than $50 \%$. This demonstrates the necessity of calibrating the bulk formulae.

Table 3. Variation of coefficient values for six cloudy-sky bulk formulae before and after calibration.

\begin{tabular}{ccccc}
\hline Bulk Formula & Coefficients & $\begin{array}{c}\text { Original } \\
\text { Coefficients }\end{array}$ & $\begin{array}{c}\text { Adjusted } \\
\text { Coefficients }\end{array}$ & $\begin{array}{c}\text { Relative } \\
\text { Difference (\%) }\end{array}$ \\
\hline Jacobs [29] & a1 & 0.26 & 0.17 & -0.36 \\
\hline \multirow{2}{*}{ MC [45] } & a2 & 0.22 & 0.12 & -0.44 \\
& b2 & 2.75 & 0.30 & -0.89 \\
\hline \multirow{2}{*}{ Lhomme [27] } & a3 & 1.03 & 1.06 & 0.03 \\
& b3 & 0.34 & 0.07 & -0.80 \\
\hline \multirow{5}{*}{ Konzelmann [28] } & a4 & 1 & 0.29 & -0.71 \\
& b4 & 4 & 0.23 & -0.94 \\
& d4 & 0.952 & 0.34 & -0.64 \\
Carmona1 [25] & e4 & 4 & 0.27 & -0.93 \\
\hline & a6 & -0.88 & 0.33 & -1.38 \\
& b6 & $5.2 \cdot 10^{-3}$ & $8.05 \cdot 10^{-4}$ & -0.85 \\
& d6 & $2.02 \cdot 10^{-3}$ & $3.90 \cdot 10^{-3}$ & 0.93 \\
\hline \multirow{2}{*}{ Carmona2 [25] } & a7 & -0.34 & 0.55 & -2.61 \\
& b7 & $3.36 \cdot 10^{-3}$ & $5.05 \cdot 10^{-4}$ & -0.85 \\
& d7 & $1.94 \cdot 10^{-3}$ & $2.57 \cdot 10^{-3}$ & 0.32 \\
& e7 & 0.213 & $5.6 \cdot 10^{-2}$ & -0.74 \\
\hline
\end{tabular}


The validation results are shown in Figure 2. Most of the samples are distributed around the 1:1 line except a small number of samples that have larger deviations. The statistical performance is shown in Table 4 . The BIAS values of the calibrated bulk formulae range from $-6.91 \mathrm{~W} \cdot \mathrm{m}^{-2}$ to $4.44 \mathrm{~W} \cdot \mathrm{m}^{-2}$, with an average of $2.77 \mathrm{~W} \cdot \mathrm{m}^{-2}$, whereas those of the original bulk formulae are between $-25.55 \mathrm{~W} \cdot \mathrm{m}^{-2}$ and $29.76 \mathrm{~W} \cdot \mathrm{m}^{-2}$, with an average of $14.40 \mathrm{~W} \cdot \mathrm{m}^{-2}$. The RMSE of the calibrated bulk formulae range from $20.13 \mathrm{~W} \cdot \mathrm{m}^{-2}$ to $26.58 \mathrm{~W} \cdot \mathrm{m}^{-2}$, with an average of $24.27 \mathrm{~W} \cdot \mathrm{m}^{-2}$, whereas those of the original bulk formulae are between $26.58 \mathrm{~W} \cdot \mathrm{m}^{-2}$ and $47.15 \mathrm{~W} \cdot \mathrm{m}^{-2}$, with a mean of $33.30 \mathrm{~W} \cdot \mathrm{m}^{-2}$. The $\mathrm{R}^{2}$ are slightly improved after calibration. The bulk formula of Carmona2 performs the best, with the lowest zero BIAS and RMSE of $20.13 \mathrm{~W} \cdot \mathrm{m}^{-2}$ and second highest $\mathrm{R}^{2}$ of 0.87 .

Table 4. Validation results of seven calibrated cloudy-sky bulk formulae and the BMA method. The results for the original cloudy-sky bulk formulae and BMA method are also provided.

\begin{tabular}{ccccccc}
\hline \multirow{2}{*}{ Bulk Formula } & \multicolumn{3}{c}{ Original } & \multicolumn{3}{c}{ Calibrated } \\
\cline { 2 - 7 } & BIAS & RMSE & $\mathbf{R}^{\mathbf{2}}$ & BIAS & RMSE & $\mathbf{R}^{\mathbf{2}}$ \\
\hline Jacobs [29] & 7.63 & 31.25 & 0.85 & -6.91 & 26.36 & 0.86 \\
MC [45] & -16.78 & 31.68 & 0.85 & -2.70 & 24.62 & 0.87 \\
Lhomme [27] & 29.76 & 47.15 & 0.83 & -2.69 & 24.65 & 0.87 \\
Konzelmann [28] & -25.55 & 34.68 & 0.86 & -1.69 & 23.32 & 0.87 \\
Crawford [45] & 0.96 & 26.58 & 0.82 & 0.96 & 26.58 & 0.82 \\
Carmona1 [25] & -8.80 & 31.72 & 0.79 & 4.44 & 24.21 & 0.83 \\
Carmona2 [25] & -11.33 & 30.01 & 0.83 & 0.00 & 20.13 & 0.87 \\
BMA & -5.47 & 27.28 & 0.85 & -1.08 & 21.99 & 0.88 \\
\hline
\end{tabular}

The BMA yields balanced results, and its accuracy is only slightly worse than the bulk formula of Carmona 2 and better than the other bulk formulae, with the highest $\mathrm{R}^{2}$ of 0.88 , second-lowest RMSE of $21.99 \mathrm{~W} \cdot \mathrm{m}^{-2}$, and a relatively lower BIAS of $-1.08 \mathrm{~W} \cdot \mathrm{m}^{-2}$. The balance indicates that the three indicators of BMA are better than the average of those for seven selected bulk formulae. The performances of other bulk formulae are also acceptable, with BIAS ranges from $-6.91 \mathrm{~W} \cdot \mathrm{m}^{-2}$ to $4.44 \mathrm{~W} \cdot \mathrm{m}^{-2}$, RMSE ranges from $23.32 \mathrm{~W} \cdot \mathrm{m}^{-2}$ to $26.58 \mathrm{~W} \cdot \mathrm{m}^{-2}$, and $\mathrm{R}^{2}$ around 0.85 . The coefficients of bulk formulae of Carmona are tunable during the calibration, whereas the SDLR $_{c l r}$ in other bulk formulae is provided as a priori and only the coefficients related to cloud fraction are tunable. This partly explains the good performance of Carmona2. Note the bulk formula of Crawford and Duchon [26] do not need calibration. The accuracy is acceptable, with a BIAS, RMSE and $\mathrm{R}^{2}$ of $0.96 \mathrm{~W} \cdot \mathrm{m}^{-2}, 26.58 \mathrm{~W} \cdot \mathrm{m}^{-2}$ and 0.82 , respectively. Therefore, it is a good choice if sufficient data to calibrate the bulk formulae are lacking. 

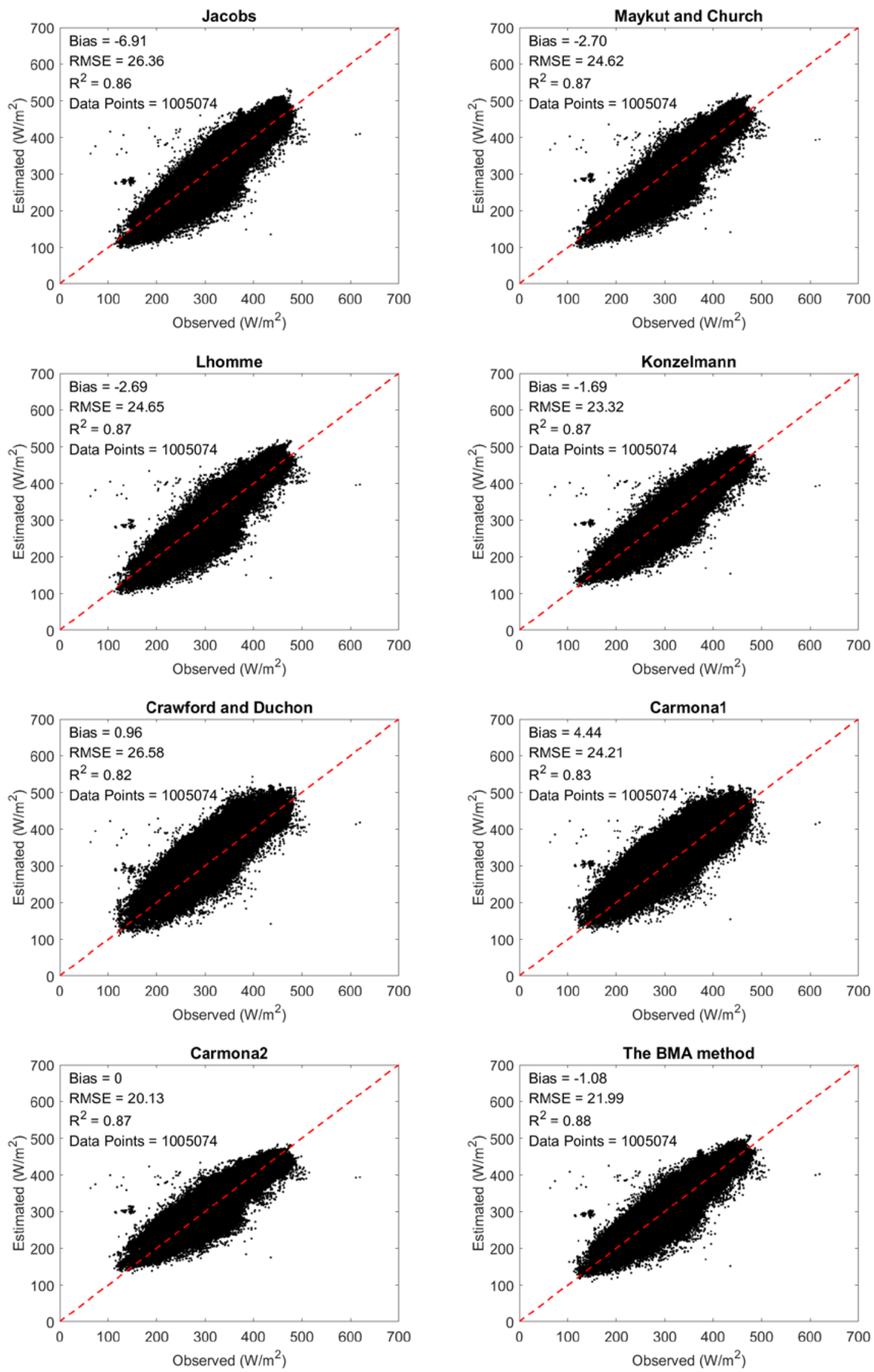

Figure 2. Validation results of SDLR estimate using seven calibrated bulk formulae and the Bayesian model averaging (BMA) method. 


\subsection{Effects of Climate Type}

Bulk formulae mainly depend on the screen-level air temperature, relative humidity and cloud properties (e.g., cloud fraction) $[15,18,26]$. The primary criteria for climatic type classification are temperature and precipitation. As a result, we divided the sites as nine groups according to the Koppen climate classification system, including Af (tropical rainforest climate, 3 sites), Am (tropical monsoon climate, 1 site), Aw (tropical wet and dry or savanna climate, 2 sites), BS (semiarid, 5 sites), BW (desert climate, 3 sites), Cf (temperate or subtropical hot summer climates, 9 sites), Cs (Mediterranean climates, 2 sites), Df (warm summer continental climates, 13 sites), and ET (tundra climate, 5 sites). The performance of the cloudy-sky bulk formulae and BMA method were investigated considering different climate types.

As shown in Figure 3, there are large fluctuations in the BIAS and RMSE plots. At first glance, we cannot determine which bulk scheme is the best. Table 5 shows that all methods overestimate SDLR when the climate type is Cf and underestimate SDLR for the Cs and ET climate types. That bulk formulae appear to overestimate SDLR under hot and warm climates and underestimate SDLR when the atmosphere is dry and cold. The absolute value of the BIAS of Carmona1 is the lowest when the climate type is Af, Aw, Cs, and ET; the RMSE of Carmona2 is the lowest except when the climate type is Am, BS and BW. BMA achieves a balanced BIAS and RMSE between the best and worst model for each climate type and has a good performance in the $\mathrm{R}^{2}$. The BIAS, RMSE and $\mathrm{R}^{2}$ of Carmona1 range from -8.85 to $14.65 \mathrm{~W} \cdot \mathrm{m}^{-2}, 13.02$ to $37.68 \mathrm{~W} \cdot \mathrm{m}^{-2}$, and 0.19 to 0.73 , respectively. The BIAS, RMSE, and $\mathrm{R}^{2}$ of Carmona2 range from -10.02 to $7.56 \mathrm{~W} \cdot \mathrm{m}^{-2}, 10.69$ to $28.91 \mathrm{~W} \cdot \mathrm{m}^{-2}$, and 0.18 to 0.79 , respectively. The BIAS, RMSE, and $\mathrm{R}^{2}$ of BMA range from -13.49 to $7.57 \mathrm{~W} \cdot \mathrm{m}^{-2}, 12.23$ to $30.96 \mathrm{~W} \cdot \mathrm{m}^{-2}$, and 0.20 to 0.81 , respectively. Based on the BIAS values in Table 5, we can identify the best bulk formula for each climatic type. Carmona1 performs the best over Af, Aw, Cs, and ET, Carmona2 performs better over BW and DF, Lhomme performs better over Am, MC performs better over BS, and Jacobs performs well over Cf. The performance of Carmona1 and Carmona2 are generally relatively better than the other methods. Due to the scarcity of the ground measured SDLR, the number of sites for each climate type are different. We did not find a clear relationship between the number of sites and the performance of bulk formulae over each climate type. We will explore this relationship once we accumulate abundant data.
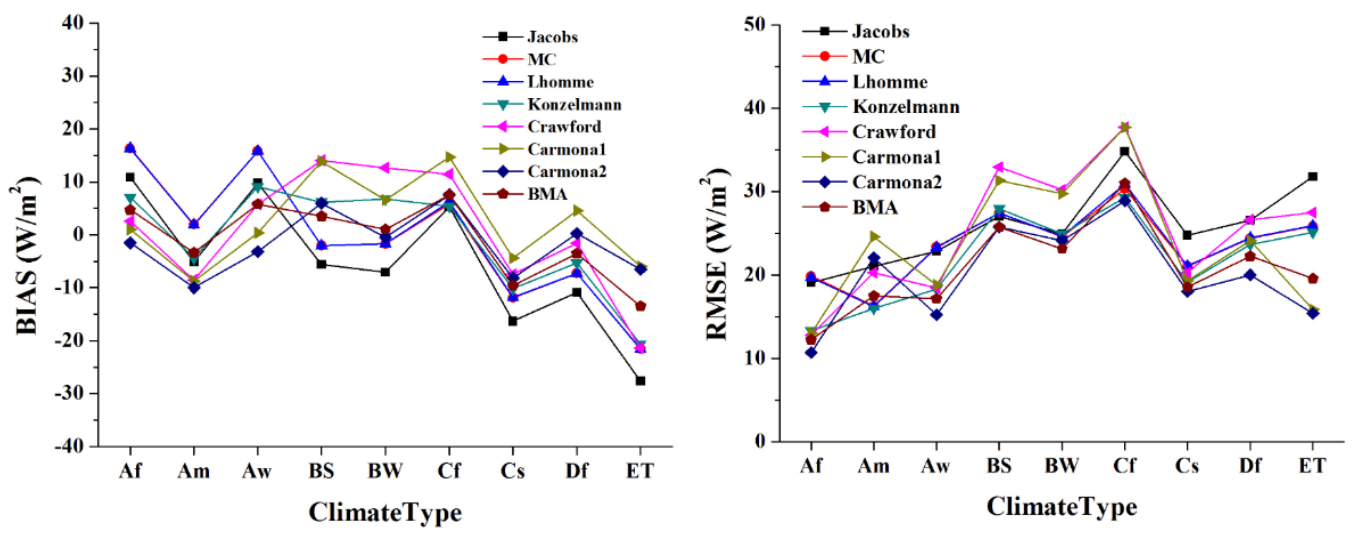

Figure 3. The performance of seven cloudy-sky bulk formulae and the BMA method over different climate types. 
Table 5. Statistical results of seven cloudy-sky bulk formulae and the BMA method over different climate types. Af: tropical rainforest climate; Am: tropical monsoon climate; Aw: tropical wet and dry or savanna climate; BS: semiarid; BW: desert climate; Cf: temperate or subtropical hot summer climates; Cs: Mediterranean climates; Df: warm summer continental climates; and ET tundra climate.

\begin{tabular}{|c|c|c|c|c|c|c|c|c|}
\hline \multirow{2}{*}{ Climate Type } & \multicolumn{8}{|c|}{ BIAS (W/m²) } \\
\hline & Jacobs & MC & Lhomme & Konzelmann & Crawford & Carmona1 & Carmona2 & BMA \\
\hline Af & 10.87 & 16.35 & 16.29 & 7.11 & 2.59 & 1.00 & -1.55 & 4.71 \\
\hline Am & 5.15 & 1.97 & 1.83 & -4.42 & -8.55 & -8.75 & -10.02 & -3.40 \\
\hline Aw & 9.71 & 15.82 & 15.75 & 9.09 & 5.70 & 0.40 & -3.16 & 5.76 \\
\hline BS & -5.61 & -2.05 & -2.06 & 6.16 & 14.08 & 13.88 & 5.97 & 3.51 \\
\hline BW & -7.11 & -1.72 & -1.73 & 6.79 & 12.69 & 6.59 & -0.52 & 1.05 \\
\hline $\mathrm{Cf}$ & 5.28 & 5.81 & 6.21 & 5.40 & 11.46 & 14.65 & 7.56 & 7.57 \\
\hline Cs & -16.36 & -11.90 & -11.88 & -10.17 & -7.48 & -4.45 & -8.18 & -9.57 \\
\hline Df & -10.89 & -7.27 & -7.27 & -5.37 & -1.63 & 4.54 & 0.26 & -3.54 \\
\hline ET & -27.66 & -21.53 & -21.59 & -20.65 & -21.37 & -6.02 & -6.52 & -13.49 \\
\hline \multirow{2}{*}{ Climate Type } & \multicolumn{8}{|c|}{$\operatorname{RMSE}\left(W / \mathrm{m}^{2}\right)$} \\
\hline & Jacobs & MC & Lhomme & Konzelmann & Crawford & Carmona1 & Carmona2 & BMA \\
\hline Af & 19.07 & 19.84 & 19.68 & 13.29 & 12.79 & 13.02 & 10.69 & 12.23 \\
\hline $\mathrm{Am}$ & 21.03 & 16.26 & 16.18 & 16.00 & 20.26 & 24.59 & 22.07 & 17.48 \\
\hline Aw & 22.84 & 23.39 & 23.28 & 18.28 & 18.42 & 18.78 & 15.22 & 17.16 \\
\hline BS & 27.05 & 27.45 & 27.43 & 27.97 & 32.95 & 31.32 & 25.76 & 25.74 \\
\hline BW & 24.94 & 24.56 & 24.62 & 24.96 & 30.20 & 29.75 & 24.12 & 23.15 \\
\hline $\mathrm{Cf}$ & 34.79 & 30.31 & 30.89 & 29.29 & 37.72 & 37.68 & 28.91 & 30.96 \\
\hline Cs & 24.77 & 21.05 & 21.09 & 19.10 & 20.26 & 19.33 & 18.04 & 18.52 \\
\hline Df & 26.54 & 24.39 & 24.47 & 23.63 & 26.63 & 24.13 & 20.01 & 22.24 \\
\hline ET & 31.79 & 25.84 & 25.89 & 25.10 & 27.49 & 15.84 & 15.40 & 19.56 \\
\hline \multirow{2}{*}{ Climate Type } & \multicolumn{8}{|c|}{$\mathbf{R}^{2}$} \\
\hline & Jacobs & MC & Lhomme & Konzelmann & Crawford & Carmona1 & Carmona2 & BMA \\
\hline Af & 0.19 & 0.16 & 0.17 & 0.15 & 0.18 & 0.19 & 0.18 & 0.20 \\
\hline Am & 0.52 & 0.74 & 0.75 & 0.81 & 0.62 & 0.39 & 0.62 & 0.70 \\
\hline Aw & 0.34 & 0.32 & 0.32 & 0.31 & 0.31 & 0.32 & 0.33 & 0.35 \\
\hline BS & 0.76 & 0.73 & 0.73 & 0.73 & 0.72 & 0.71 & 0.74 & 0.75 \\
\hline BW & 0.74 & 0.72 & 0.72 & 0.73 & 0.70 & 0.64 & 0.71 & 0.74 \\
\hline $\mathrm{Cf}$ & 0.66 & 0.73 & 0.72 & 0.71 & 0.58 & 0.57 & 0.70 & 0.69 \\
\hline Cs & 0.79 & 0.80 & 0.80 & 0.81 & 0.78 & 0.73 & 0.79 & 0.81 \\
\hline Df & 0.78 & 0.79 & 0.79 & 0.77 & 0.71 & 0.73 & 0.79 & 0.78 \\
\hline ET & 0.73 & 0.75 & 0.75 & 0.74 & 0.67 & 0.73 & 0.75 & 0.75 \\
\hline
\end{tabular}

\subsection{Effects of Land Cover Type}

The land cover type is another factor that regulates Earth-atmosphere interactions. We divided the sites into five types, i.e., desert ( 3 sites), bare land (4 sites), cropland (4 sites), grass (12 sites), and forest (14 sites), to investigate the accuracy of the bulk formula and the BMA method. The evaluation results are shown in Figure 4. Similar to Figure 3, there are larger spread in the BIAS and RMSE. Considering the BIAS and RMSE of each bulk formulae and the BMA over all land cover types, it is difficult to conclude which one performs the best or the worst as a whole. The statistical results in Table 6 show that all methods underestimate the SDLR over bare land and forest, with BIAS ranging from -27.66 to $-2.65 \mathrm{~W} \cdot \mathrm{m}^{-2}$, and overestimate the SDLR over Grassland, with BIAS ranging from 2.89 to $10.63 \mathrm{~W} \cdot \mathrm{m}^{-2}$. The $\mathrm{R}^{2}$ of all methods are larger than 0.64 . The RMSE of Carmona2 is better than that of the other methods under most conditions. According to the BIAS values, Jacobs performs the best over grassland, Carmona1 performs well over bare land and forest, and Carmona2 performs well over desert and cropland. BMA achieves a balanced BIAS and RMSE between the best and worst model for each land cover type. 

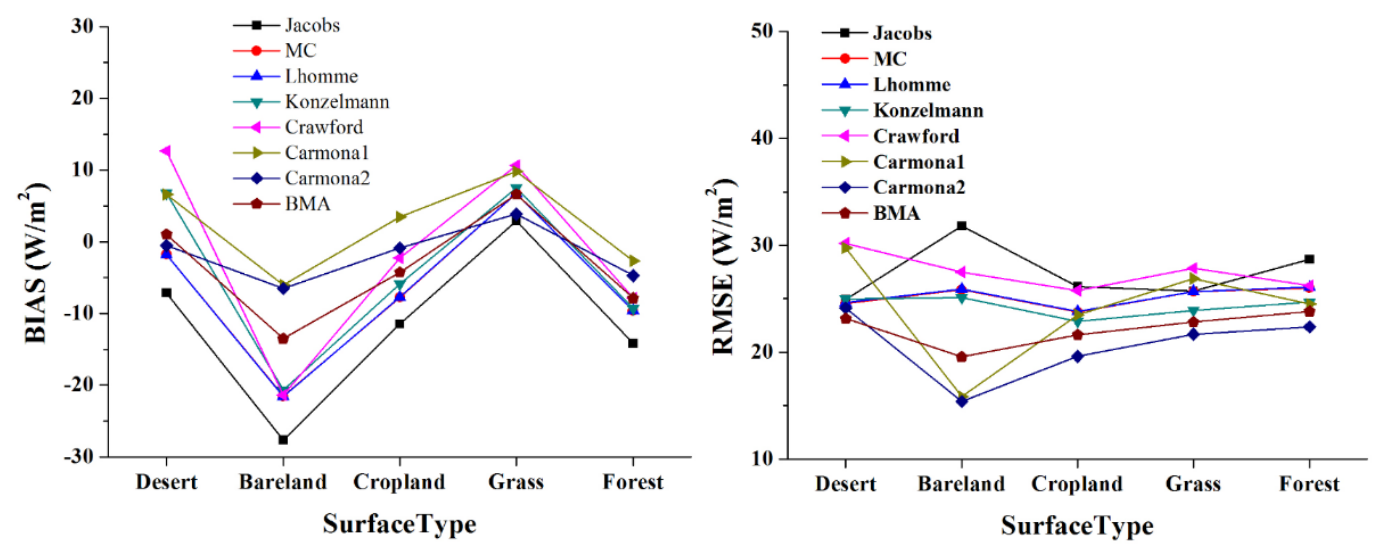

Figure 4. Validation results of seven bulk formulae and the BMA method over different land cover types.

Table 6. Statistical results of seven parameterization schemes and the BMA method over different land cover types.

\begin{tabular}{|c|c|c|c|c|c|c|c|c|}
\hline \multirow{2}{*}{$\begin{array}{c}\text { Land Cover } \\
\text { Type }\end{array}$} & \multicolumn{8}{|c|}{ BIAS $\left(\mathrm{W} / \mathrm{m}^{2}\right)$} \\
\hline & Jacobs & MC & Lhomme & Konzelmann & Crawford & Carmona1 & Carmona2 & BMA \\
\hline Desert & -7.11 & -1.72 & -1.73 & 6.79 & 12.69 & 6.59 & -0.52 & 1.05 \\
\hline Bare land & -27.66 & -21.53 & -21.59 & -20.65 & -21.37 & -6.02 & -6.52 & -13.49 \\
\hline Cropland & -11.46 & -7.74 & -7.73 & -5.87 & -2.21 & 3.46 & -0.85 & -4.25 \\
\hline Grassland & 2.89 & 6.72 & 6.74 & 7.53 & 10.63 & 9.79 & 3.87 & 6.62 \\
\hline Forest & -14.16 & -9.59 & -9.58 & -9.28 & -7.83 & -2.65 & -4.71 & -7.86 \\
\hline \multirow{2}{*}{$\begin{array}{c}\text { Land Cover } \\
\text { Type }\end{array}$} & \multicolumn{8}{|c|}{$\operatorname{RMSE}\left(\mathrm{W} / \mathrm{m}^{2}\right)$} \\
\hline & Jacobs & MC & Lhomme & Konzelmann & Crawford & Carmona1 & Carmona2 & BMA \\
\hline Desert & 24.94 & 24.56 & 24.62 & 24.96 & 30.20 & 29.75 & 24.12 & 23.15 \\
\hline Bare land & 31.79 & 25.84 & 25.89 & 25.10 & 27.49 & 15.84 & 15.40 & 19.56 \\
\hline Cropland & 26.10 & 23.74 & 23.81 & 22.88 & 25.77 & 23.49 & 19.60 & 21.63 \\
\hline Grassland & 25.72 & 25.66 & 25.69 & 23.89 & 27.84 & 26.88 & 21.68 & 22.82 \\
\hline Forest & 28.66 & 25.99 & 26.06 & 24.70 & 26.20 & 24.50 & 22.38 & 23.80 \\
\hline \multirow{2}{*}{$\begin{array}{c}\text { Land Cover } \\
\text { Type }\end{array}$} & \multicolumn{8}{|c|}{$\mathbf{R}^{2}$} \\
\hline & Jacobs & MC & Lhomme & Konzelmann & Crawford & Carmona1 & Carmona2 & BMA \\
\hline Desert & 0.74 & 0.72 & 0.72 & 0.73 & 0.70 & 0.64 & 0.71 & 0.74 \\
\hline Bare land & 0.73 & 0.75 & 0.75 & 0.74 & 0.67 & 0.73 & 0.75 & 0.75 \\
\hline Cropland & 0.78 & 0.79 & 0.79 & 0.78 & 0.72 & 0.73 & 0.79 & 0.79 \\
\hline Grassland & 0.90 & 0.90 & 0.90 & 0.90 & 0.86 & 0.86 & 0.90 & 0.90 \\
\hline Forest & 0.85 & 0.86 & 0.86 & 0.85 & 0.81 & 0.82 & 0.85 & 0.85 \\
\hline
\end{tabular}

\subsection{Effects of Surface Elevation}

The vertical zonality is an important component of the rule of territorial differentiation. The driving factors behind the vertical zonality are water vapor and temperature, and elevation is a direct quantitative index of vertical zonality. We divided the sites into four categories according to the elevation range ( $\leq 500 \mathrm{~m}$ ( 23 sites), $500-1000 \mathrm{~m}$ (8 sites), 1000-3000 m (7 sites), and $\geq 3000 \mathrm{~m}$ (6 sites)) and assessed the cloudy-sky bulk formulae and BMA method. Figure 5 shows a trend that the absolute values of the BIAS and the RMSE increase with surface elevation. Table 7 shows that the cloudy-sky bulk formulae perform best when the surface elevation is less than $500 \mathrm{~m}$. The BIAS ranges from -7.25 to $0.56 \mathrm{~W} \cdot \mathrm{m}^{-2}$, the RMSE ranges from 16.91 to $25.21 \mathrm{~W} \cdot \mathrm{m}^{-2}$, and $\mathrm{R}^{2}$ is approximately 0.9 . The bulk formulae perform the worst when the surface elevation is higher than $3000 \mathrm{~m}$. The bulk formulae underestimate the SDLR when the elevation is higher than $3000 \mathrm{~m}$. The BIAS ranges from -45.72 to $-14.88 \mathrm{~W} \cdot \mathrm{m}^{-2}$, the RMSE ranges from 38.85 to $59.41 \mathrm{~W} \cdot \mathrm{m}^{-2}$, and $\mathrm{R}^{2}$ is approximately 0.6 . The BMA 
achieves a balanced BIAS and RMSE between the best and worst model for each climate type. This is consistent with the climate and surface type evaluation results.
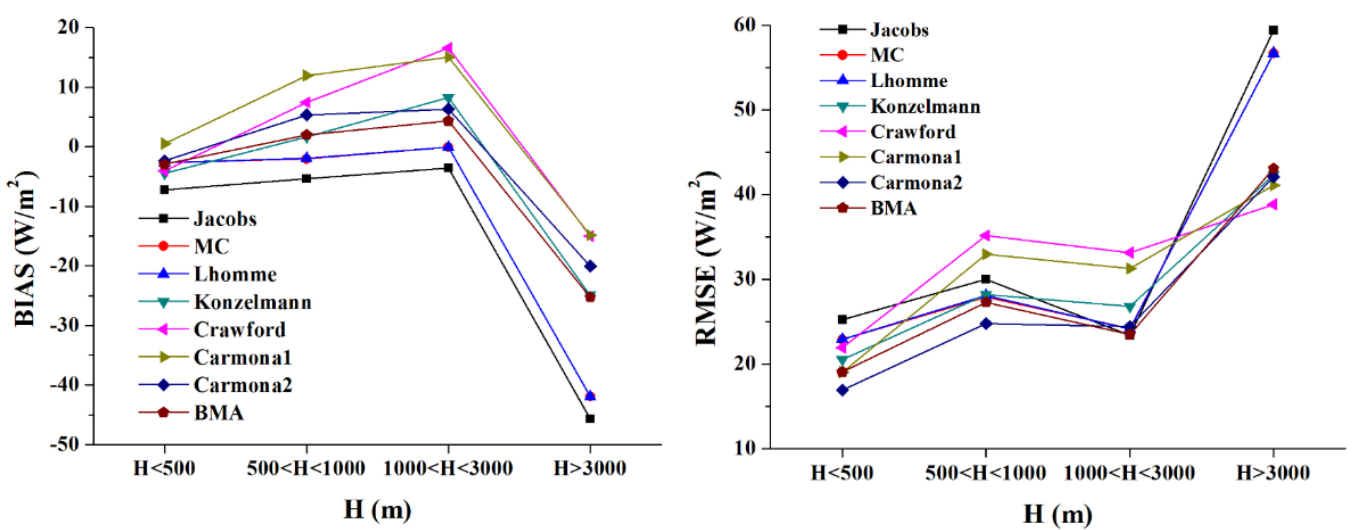

Figure 5. Validation results of the seven bulk formulae and the BMA method at different surface elevations.

Table 7. Statistical results of the seven bulk formulae and the BMA method over different surface elevations.

\begin{tabular}{|c|c|c|c|c|c|c|c|c|}
\hline \multirow{2}{*}{ Elevation } & \multicolumn{8}{|c|}{ BIAS $\left(\mathrm{W} / \mathrm{m}^{2}\right)$} \\
\hline & Jacobs & MC & Lhomme & Konzelmann & Crawford & Carmona1 & Carmona2 & BMA \\
\hline $\mathrm{H}<500$ & -7.24 & -2.66 & -2.66 & -4.45 & -4.07 & 0.56 & -2.31 & -2.92 \\
\hline $500<\mathrm{H}<1000$ & -5.38 & -2.04 & -1.93 & 1.66 & 7.42 & 11.97 & 5.36 & 2.04 \\
\hline $1000<\mathrm{H}<3000$ & -3.57 & -0.05 & -0.08 & 8.26 & 16.60 & 15.07 & 6.34 & 4.36 \\
\hline $\mathrm{H}>3000$ & -45.72 & -41.96 & -41.90 & -24.92 & -15.01 & -14.88 & -20.03 & -25.27 \\
\hline \multirow{2}{*}{ Elevation } & \multicolumn{8}{|c|}{$\operatorname{RMSE}\left(W / m^{2}\right)$} \\
\hline & Jacobs & MC & Lhomme & Konzelmann & Crawford & Carmona1 & Carmona2 & BMA \\
\hline $\mathrm{H}<500$ & 25.21 & 22.89 & 22.92 & 20.52 & 21.93 & 19.01 & 16.91 & 19.05 \\
\hline $500<\mathrm{H}<1000$ & 29.99 & 27.93 & 28.06 & 28.21 & 35.14 & 32.96 & 24.75 & 27.26 \\
\hline $1000<\mathrm{H}<3000$ & 23.34 & 24.16 & 24.13 & 26.82 & 33.15 & 31.24 & 24.38 & 23.50 \\
\hline $\mathrm{H}>3000$ & 59.41 & 56.67 & 56.71 & 42.33 & 38.85 & 41.08 & 42.11 & 43.09 \\
\hline \multirow{2}{*}{ Elevation } & \multicolumn{8}{|c|}{$\mathbf{R}^{2}$} \\
\hline & Jacobs & MC & Lhomme & Konzelmann & Crawford & Carmona1 & Carmona2 & BMA \\
\hline $\mathrm{H}<500$ & 0.91 & 0.92 & 0.92 & 0.91 & 0.89 & 0.89 & 0.92 & 0.91 \\
\hline $500<\mathrm{H}<1000$ & 0.70 & 0.72 & 0.72 & 0.69 & 0.60 & 0.61 & 0.72 & 0.70 \\
\hline $1000<\mathrm{H}<3000$ & 0.80 & 0.77 & 0.78 & 0.75 & 0.73 & 0.72 & 0.79 & 0.79 \\
\hline $\mathrm{H}>3000$ & 0.60 & 0.59 & 0.59 & 0.65 & 0.65 & 0.59 & 0.59 & 0.64 \\
\hline
\end{tabular}

The air temperature, relative humidity and cloud fraction are used to predict cloudy-sky SDLR in the selected bulk formulae. The uncertainties of the input variables propagate into the predicted SDLR and cause unpredictability [50]. Even most of the clear-sky SDLR is emitted within the lowest layer of the atmosphere, air temperature and relative humidity at screen level cannot fully reflect the variability of the upper level temperature and water content. The accuracy of predicted SDLR is improved by incorporating the total precipitable water (TPW) [50,51]. Other factors, such as uncertainties in the cloud fraction, aerosol loads, heatwaves in hot summers, and temperature inversions in the lower atmospheric levels during cold winter night, also affect the predictability of the bulk formulae [27,34,50,52]. The positive BIAS over climate types Af and Cf might result from strong unstable air temperatures with high humidifies, and negative BIAS over climate type ET might relate to dry atmospheric conditions and strong inversions; In addition, the negative BIAS over land cover type bare land may be incurred by strong atmospheric inversions. Furthermore, the method 
of estimating cloud fraction with Equation (2) cannot account perfectly for cloudiness. For example, thin cloud types like cirrus have higher solar transmissivity, and resulting in an underestimating of cloud cover as well as SDLR. This partly explains the negative BIAS in SDLR when surface elevation is higher than $3000 \mathrm{~m}$. Another possible explanation may be that other atmospheric constituents (e.g., ozone and $\mathrm{CO}_{2}$ ) have relatively large contributions to the SDLR, but this contribution is not considered by the bulk formulae $[4,15]$.

According to the investigation results on the impacts of climate type, land cover type and surface elevation, it did not provide a clear guidance on how to identify an optimal bulk formula under certain circumstances (climate type, land cover type, and surface elevation). For example, we may have three different bulk formulae to calculate SDLR for a specific site because this site belongs to certain climate type, land cover type and surface elevation at the same time. We can select the one with the best performance. Meanwhile, it is also advisable to integrate the bulk formulae via BMA, whose performance has been verified in Section 3. The BMA method conducts a weighted average of the individual bulk formula. The weight of each bulk formula is derived from the calibration results, and can reflect the predictive performance of each bulk formula. Therefore, the performance of the BMA is close to bulk formula that performs best, and better than the arithmetic average of those for seven selected bulk formulae.

\section{Conclusions}

SDLR is one of the four components required to calculate the Earth's surface radiation budget. Bulk formulae are widely used to estimate all-sky SDLR due to the simple, readily available inputs and acceptable accuracy from local to regional scales. The accuracy and applicability of seven widely used bulk formulae were investigated using ground measurements collected from 44 globally distributed flux measurement sites in five networks. The BMA method was introduced to integrate multiple bulk formulae to obtain an estimate of cloudy-sky SDLR for the first time. The accuracy and applicability of the BMA method were also investigated using the same data. The following conclusions can be drawn from this study:

It is vital to calibrate cloudy-sky bulk formulae before use. If representative data to calibrate the bulk formulae are lacking, the bulk formula of Crawford and Duchon [26] is a good choice because it can achieve acceptable accuracy as a whole without local calibration.

Overall, the bulk formula of Carmona2 (i.e., the second multiple linear regression model of Carmona et al. [25]) performs the best, with a BIAS of zero, an RMSE of $20.13 \mathrm{~W} \cdot \mathrm{m}^{-2}$, and an $\mathrm{R}^{2}$ of 0.87 .

The BMA method conducts a weighted average of the individual bulk formula. The weight of each bulk formula is derived from the calibration results, and can reflect the predictive performance of each bulk formula. Therefore, the BMA method can achieve balanced results that are close to those of Carmona2 and better than the arithmetic average of those for seven selected bulk formulae, with a BIAS, RMSE and $\mathrm{R} 2$ of $-1.08 \mathrm{~W} \cdot \mathrm{m}^{-2}, 21.99 \mathrm{~W} \cdot \mathrm{m}^{-2}$ and 0.87 , respectively.

The investigation results on the impacts of climate type, land cover type and surface elevation did not provide a clear guidance on how to identify the bulk formula with an optimal performance at certain circumstances (climate type, land cover type and surface elevation). For example, we may have three different bulk formulae to calculate SDLR for a specific site because this site belongs to certain climate type, land cover type and surface elevation at the same time. We can select the one with the best performance or integrate the bulk formulae via BMA.

To summary, a bulk formula that can be successfully applied everywhere does not exist. The best and worst methods may differ under different climate types, land cover types and surface elevations. Thus, the best bulk formula should be site-specific.

Author Contributions: Conceptualization, J.C.; methodology, J.C. and Y.G.; validation, Y.G. and F.Y.; writing-original draft preparation, Y.F. and Y.G.; writing-review and editing, J.C.; supervision, J.C.; funding acquisition, J.C. 
Funding: This work was partly supported by the National Key Research and Development Program of China via grant 2016YFA0600101, the National Natural Science Foundation of China via grant 41771365 and the Special Fund for Young Talents of the State Key Laboratory of Remote Sensing Sciences via grant 17ZY-02.

Acknowledgments: The AmeriFlux data was downloaded from http://asiaflux.yonsei.kr/index.html, the AsiaFlux data was downloaded from https://db.cger.nies.go.jp/asiafluxdb/, the CEOP data was downloaded from http:/ / aan.suiri.tsukuba.ac.jp, the Fluxnet data was downloaded from http:/ / daac.ornl.gov/get_data.shtml, and the SURFRAD data was downloaded from http:/ / www.srrb.noaa.gov, respectively.

Conflicts of Interest: The authors declare no conflict of interest.

\section{References}

1. Liang, S.; Wang, K.; Zhang, X.; Wild, M. Review of estimation of land surface radiation and energy budgets from ground measurements, remote sensing and model simulation. IEEE J. Sel. Top. Earth Obs. Remote Sens. 2010, 3, 225-240. [CrossRef]

2. Barkstrom, B.R. The earth radiation budget experiment (erbe). Bull. Am. Meteor. Sci. 1984, 65, 1170-1185. [CrossRef]

3. Cheng, J.; Liang, S.; Wang, W. 5.09—Surface downward longwave radiation. In Comprehensive Remote Sensing; Liang, S., Ed.; Elsevier: Oxford, UK, 2018; pp. 196-216.

4. Wang, K.; Dickinson, R.E. Global atmospheric downward longwave radiation at the surface from ground-based observations, satellite retrievals, and reanalyses. Rev. Geophys. 2013, 51, 150-185. [CrossRef]

5. Guo, Y.; Cheng, J. Feasibility of estimating cloudy-sky surface longwave net radiation using satellite-derived surface shortwave net radiation. Remote Sens. 2018, 10, 596. [CrossRef]

6. Stubenrauch, C.J.; Rossow, W.B.; Kinne, S.; Ackerman, S.; Cesana, G.; Chepfer, H.; Girolamo, L.D.; Getzewich, B.; Guignard, A.; Heidinger, A. Assessment of global cloud datasets from satellites: Project and database initiated by the gewex radiation panel. Bull. Am. Meteorol. Soc. 2013, 94, 1031-1049. [CrossRef]

7. Viúdez-Mora, A.; Costa-Surós, M.; Calbó, J.; González, J.A. Modeling atmospheric longwave radiation at the surface during overcast skies: The role of cloud base height. J. Geophys. Res. Atmos. 2015, 120, 199-214. [CrossRef]

8. Wang, T.; Shi, J.; Yu, Y.; Husi, L.; Gao, B.; Zhou, W.; Ji, D.; Zhao, T.; Xiong, C.; Chen, L. Cloudy-sky land surface longwave downward radiation (lwdr) estimation by integrating modis and airs/amsu measurements. Remote Sens. Environ. 2018, 205, 100-111. [CrossRef]

9. Kimball, B.A.; Idso, S.B.; Aase, J.K. A model of thermal radiation from partly cloudy and overcast skies. Water Resour. Res. 1982, 18, 931-936. [CrossRef]

10. Yang, K.; He, J.; Tang, W.; Qin, J.; Cheng, C.C.K. On downward shortwave and longwave radiations over high altitude regions: Observation and modeling in the tibetan plateau. Agric. For. Meteorol. 2010, 150, 38-46. [CrossRef]

11. Diak, G.R.; Mecikalski, J.R.; Anderson, M.C.; Norman, J.M.; Kustas, W.P.; Torn, R.D.; Dewolf, R.L. Estimating land surface energy budgets from space: Review and current efforts at the university of wisconsin-Madison and usda ars. Bull. Am. Meteor. Soc. 2004, 85, 65-78. [CrossRef]

12. Schmetz, J. Towards a surface radiation climatology: Retrieval of downward irradiances from satellites. Atmos. Res. 1989, 23, 287-321. [CrossRef]

13. Ellingson, R.G. Surface longwave fluxes from satellite observations: A critical review. Remote Sens. Environ. 1995, 51, 89-97. [CrossRef]

14. Ineichen, P.; Barroso, C.S.; Geiger, B.; Hollmann, R.; Marsouin, A.; Mueller, R. Satellite application facilities irradiance products: Hourly time step comparison and validation over europe. Int. J. Remote Sens. 2009, 30, 5549-5571. [CrossRef]

15. Gupta, S.K. A parameterization for longwave surface radiation from sun-synchronous satellite data. J. Clim. 1989, 2, 305-320. [CrossRef]

16. Cheng, J.; Liang, S.; Wang, W.; Guo, Y. An efficient hybrid method for estimating clear-sky surface downward longwave radiation from modis data. J. Geophys. Res. Atmos. 2017, 122, 2616-2630. [CrossRef]

17. Trigo, I.F.; Barroso, C.; Vitervo, P.; Freitas, S.C.; Monteiro, I.T. Estimation of downward long-wave radiation at the surface combining remotely sensed data and nwp data. J. Geophys. Res. 2010, 115. [CrossRef]

18. Diak, G.R.; Bland, W.L.; Mecikalski, J.R.; Anderson, M.C. Satellite-based estimates of longwave radiation for agricultural applications. Agric. For. Meteorol. 2000, 103, 349-355. [CrossRef] 
19. Zhu, M.; Yao, T.; Yang, W.; Baiqing, X.U.; Wang, X. Evaluation of parameterizations of incoming longwave radiation in the high mountain region of the tibetan plateau. J. Appl. Meteorol. Climatol. 2017, 56, 833-848. [CrossRef]

20. Wang, K.; Liang, S. Global atmospheric downward longwave radiation over land surface under all-sky conditions from 1973 to 2008. J. Geophys. Res. Atmos. 2009, 114. [CrossRef]

21. Brunt, D. Notes on radiation in the atmosphere. Q. J. R. Meteorol. Soc. 1932, 58, 389-420. [CrossRef]

22. Brutsaert, W. On a derivable formula for long-wave radiation from clear skies. Water Resour. Res. 1975, 11, 742-744. [CrossRef]

23. Prata, A.J. A new long-wave formula for estimating downward clear-sky radiations at the surface. Q. J.R. Meteorol. Soc. 1996, 122, 1127-1151. [CrossRef]

24. Idso, S.B. A set of equations for full spectrum and 8- to 14-um and 10.5- to 12.5-um thermal radiation from cloudless skies. Water Resour. Res. 1981, 17, 295-304. [CrossRef]

25. Carmona, F.; Rivas, R.; Caselles, C. Estimation of daytime downward longwave radiation under clear and cloudy skies conditions over a sub-humid region. Appl. Clim. 2014, 115, 281-295. [CrossRef]

26. Crawford, T.M.; Duchon, C.E. An improved parameterization for estimating effective atmospheric emissivity for use in calculating daytime downwelling longwave radiation. J. Appl. Meteorol. 1999, 38, 474-480. [CrossRef]

27. Lhomme, J.P.; Vacher, J.J.; Rocheteau, A. Estimating downward long-wave radiation on the andean altiplano. Agric. For. Meteorol. 2007, 145, 139-148. [CrossRef]

28. Konzelmann, T.; van de Wal, R.S.W.; Greuell, W.; Bintanja, R.; Henneken, E.A.C.; Abe-Ouchi, A. Parameterization of global and longwave incoming radiation for the greenland ice sheet. Glob. Planet. Chang. 1994, 9, 143-164. [CrossRef]

29. Jacobs, J.D. Radiation climate of broughton island. In Energy Budget Studies in Relation to Fast-Ice Breakup Processes in Davis Strait; Bary, R.G., Jacobs, J.D., Eds.; Institute of Arctic and Alpine Research, University of Colorado: Boulder, CO, USA, 1978; pp. 105-120.

30. Josey, S.A.; Pascal, R.W.; Taylor, P.K.; Yelland, M.J.; Division, J.R. A new formula for determining the atmospheric longwave flux at the ocean surface at mid-high latitudes. J. Geophys. Res. 2003, 108. [CrossRef]

31. Kjaersgaard, J.H.; Plauborg, F.L.; Hansen, S. Comparison of models for calculating daytime long-wave irradiance using long term data set. Agric. For. Meteorol. 2007, 143, 49-63. [CrossRef]

32. Swinbank, W.C. Long-wave radiation from clear skies. Q. J. R. Meteorol. Soc. 1963, 89, 339-348. [CrossRef]

33. Korsgaard, I.R.; Mikkelsen, H.E.; Olesen, J.E. Langbølgetindstra ling. Ajmet research note 26. anish Inst. Agri-Cult. Sci. (Dan. Engl. Summ.). 1991.

34. Flerchinger, G.N.; Wei, X.; Marks, D.; Sauer, T.J.; Qiang, Y. Comparison of algorithms for incoming atmospheric long-wave radiation. Water Resour. Res. 2009, 45, 450-455. [CrossRef]

35. Dilley, A.C.; O'Brien, D.M. Estimating downward clear sky long-wave irradiance at the surface from screen temperature and precipitable water. Q. J. R. Meteorol. Soc. 2010, 124, 1391-1401. [CrossRef]

36. Ångström, A.K. A Study of the Radiation of the Atmosphere: Based upon Observations of the Nocturnal Radiation during Expeditions to Algeria and to California; Smithsonian Institution: Washington, DC, USA, 1918; Volume 65.

37. Unsworth, M.H.; Monteith, J.L. Long-wave radiation at the ground I. Angular distribution of incoming radiation. Q. J. R. Meteorol. Soc. 2010, 101, 13-24. [CrossRef]

38. Sicart, J.E.; Pomeroy, J.W.; Essery, R.L.H.; Bewley, D. Incoming longwave radiation to melting snow: Observations, sensitivity and estimation in northern environments. Hydrol. Process. 2010, 20, 3697-3708. [CrossRef]

39. Wu, H.; Tang, B.; Li, Z.-L. Impact of nonlinearity and discontinuity on the spatial scaling effects of the leaf area index retreived from remotely sensed data. Int. J. Remote Sens. 2013, 34, 3503-3519. [CrossRef]

40. Guo, Y.; Cheng, J.; Liang, S. Comprehensive assessment of parameterization methods for estimating clear-sky surface downward longwave radiation. Theor. Appl. Climatol. 2018. [CrossRef]

41. Ohmura, A.; Dutton, E.G.; Forgan, B.; Frohlich, C.; Gilgen, H.; Hegner, H.; Heimo, A.; Konig-Langlo, G.; McArthur, B.; Muller, G.; et al. Baseline surface radiation network (bsrn/wcrp): New precision radiometry for climate research. Bull. Am. Meteorol. Soc. 1998, 79, 2115-2136. [CrossRef]

42. Baldocchi, D.; Falge, E.; Gu, L.H.; Olson, R.; Hollinger, D.; Running, S.; Anthoni, P.; Bernhofer, C.; Davis, K.; Evans, R.; et al. Fluxnet: A new tool to study the temporal and spatial variability of ecosystem-scale carbon dioxide, water vapor, and energy flux densities. Bull. Am. Meteorol. Soc. 2001, 82, 2415-2434. [CrossRef] 
43. Augustine, J.A.; DeLuisi, J.J.; Long, C.N. Surfrad-a national surface radiation budget network for atmospheric research. Bull. Am. Meteorol. Soc. 2000, 81, 2341-2357. [CrossRef]

44. Ma, Y.; Fan, S.; Ishikawa, H.; Tsukamoto, O.; Yao, T.; Koike, T.; Zuo, H.; Hu, Z.; Su, Z. Diurnal and inter-monthly variation of land surface heat fluxes over the central tibetan plateau area. Theor. Appl. Climatol. 2005, 80, 259-273. [CrossRef]

45. Maykut, G.A.; Church, P.E. Radiation climate of barrow alaska, 1962-1966. J. Appl. Meteorol. 1973, 12, 620-628. [CrossRef]

46. Raftery, A.E.; Gneiting, T.; Balabdaoui, F.; Polakowski, M. Using bayesian model averaging to calibrate forecast ensembles. Mon. Weather Rev. 2005, 133, 1155-1174. [CrossRef]

47. Hoeting, H.A.; Madigan, D.; Raftery, A.E.; Volinsky, C.T. Bayesian model averaging: A tutorial. Stat. Sci. 1999, 14, 382-417.

48. Fisher, R.A. On the mathematical foundations of theoretical statistics. Philos. Trans. R. Soc. Lond. 1922, 222, 309-368. [CrossRef]

49. Mclachlan, G.J.; Krishnan, T. The EM Algorithm and Extensions, 2nd ed.; John Wiley \& Sons, Inc.: New York, NY, USA, 2007.

50. Maghrabi, A.H.; Aodahh, S.H. The effect of screen level and upper air temperatures and atmospheric moisture on the downward atmospheric radiation in the south australian region. Theor. Appl. Climatol. 2019. [CrossRef]

51. Zhou, Y.; Kratz, D.P.; Wilber, A.C.; Gupta, S.K.; Cess, R.D. An improved algorithm for retrieving surface downwelling longwave radiation from satellite measurements. J. Geophys. Res. 2007, 112. [CrossRef]

52. Formetta, G.; Bancheri, M.; David, O.; Rigon, R. Performance of site-specific parameterizations of longwave radiation. Hydrol. Earth Syst. Sci. 2016, 20, 4641-4654. [CrossRef]

(C) 2019 by the authors. Licensee MDPI, Basel, Switzerland. This article is an open access article distributed under the terms and conditions of the Creative Commons Attribution (CC BY) license (http://creativecommons.org/licenses/by/4.0/). 